\title{
Analisis Penggunaan Marker Tracking Pada Augmented Reality Huruf Hijaiyah
}

\author{
Meyti Eka Apriyani ${ }^{1}$, Miftakhul Huda ${ }^{2}$, Sandi Prasetyaningsih ${ }^{3}$ \\ 1,2,3 Jurusan Teknik Informatika, Program Studi Teknik Multimedia dan Jaringan, Politeknik Negeri Batam \\ 1,2,3 J1. Ahmad Yani, Parkway Batam Centre 29461, Batam, Indonesia \\ Email korespondensi : meyti24@gmail.com
}

Dikirim 15 Maret 2016, Diperbaiki 16 April 2016, Diterima 26 April 2016

\begin{abstract}
Abstrak - Teknologi augmented reality berdasarkan metode pelacakan (tracking) terbagi menjadi dua yaitu marker based tracking dan markerless. Kedua metode ini memiliki persamaan yaitu dipengaruhi oleh jarak pendeteksian dan intensitas cahaya dalam keberhasilannya memunculkan suatu objek. Akan tetapi belum diketahui berapa jarak yang tepat dan kondisi intensitas cahaya yang ideal bagi kedua metode tersebut. Penelitian ini diusulkan untuk menganalisis pengaruh jarak pendeteksian serta integritas cahaya terhadap metode marker based tracking dan markerless. Variasi jarak yang digunakan adalah $5 \mathrm{~cm}, 10 \mathrm{~cm}, 20 \mathrm{~cm}, 30 \mathrm{~cm}, 40 \mathrm{~cm}, 50 \mathrm{~cm}$, dan $80 \mathrm{~cm}$ sebagai sub indikator jarak pendeteksian kemudian untuk mendapatkan variasi besarnya intensitas cahaya digunakan sumber cahaya matahari, lampu berwarna kuning, merah, hijau, biru, dan putih (terang). Metode pengujian yang digunakan yaitu menentukan jarak minimum dan jarak maksimum pendeteksian serta menentukan besarnya intensitas cahaya untuk memunculkan suatu objek. Hasil pengujian ini adalah jarak minimum dan maksimum pendeteksian serta intensitas cahaya yang didapatkan untuk kedua metode yang diusulkan yaitu marker based tracking memiliki rata-rata jarak minimum $7.5 \mathrm{~cm}$ dan maksimum $80.5 \mathrm{~cm}$. Sedangkan markerless rata-rata jarak minimum $3.8 \mathrm{~cm}$ dan maksimum $300 \mathrm{~cm}$. Sistem dapat memunculkan objek pada intensitas 97 lux -1605 lux.
\end{abstract}

Kata kunci - Augmented Reality, Marker Based Tracking, Markerless, Jarak Pendeteksian, Intensitas Cahaya.

Abstract - Augmented reality technology based tracking method (tracking) is divided into two marker-based tracking and Markerless. Both of these methods have in common is affected by the detection distance and the intensity of light in its success led to an object. But unknown what the exact distance and light intensity conditions were ideal for both methods. This study proposed to analyze the effect of distance detection and integrity light on the methods of marker-based tracking and Variations distance used is $5 \mathrm{~cm}, 10 \mathrm{~cm}, 20 \mathrm{~cm}, 30 \mathrm{~cm}$, $40 \mathrm{~cm}, 50 \mathrm{~cm}$, and $80 \mathrm{~cm}$ as sub-indicators within the detection later to get variations in the magnitude of the intensity of the light used light source sun, light yellow, red, green, blue, and white (light). Testing methods were used that determines the minimum distance and maximum distance detection and determine the amount of light intensity to bring an object. The results of this testing is the minimum and maximum distance of detection and light intensity are obtained for both the proposed method, the marker-based tracking has average minimum distance of $7.5 \mathrm{~cm}$ and a maximum of $80.5 \mathrm{~cm}$. Markerless while the average minimum distance of $3.8 \mathrm{~cm}$ and a maximum of $300 \mathrm{~cm}$. The system can give rise to an object on the intensity of 97 lux -1605 lux

Keywords - Augmented Reality, Marker Based Tracking, Markerless, Detection Distance, Light Intensity.

\section{PENDAHULUAN}

Perkembangan teknologi yang pesat di zaman ini membawa dampak yang signifikan untuk berbagai jenis teknologi dan penemuan baru sebagai solusi untuk mengatasi berbagai permasalahan kehidupan. Hal inilah yang mendorong manusia membutuhkan sebuah media yang dapat digunakan untuk menyelesaikan masalah dengan cepat dan efisien. Salah satu contohnya adalah media untuk memperkenalkan huruf hijaiyah dengan cepat dan menarik kepada anak-anak usia dini yang menimba ilmu di Taman Pendidikan Alqur'an (TPA) maupun
Taman Kanak-kanak (TK). Dalam sebuah penelitian yang menyatakan bahwa dari hasil survey yang dilakukan kepada 10 TPA yang tergabung dalam Forum Komunikasi TPQ se-Kecamatan Karanganyar (FORSIKA), hasil interview kepada pimpinan TPA An-Nur Daleman menyatakan bahwa selama ini santri di TPA An-Nur Daleman masih menggunakan buku iqro' sebagai media pembelajaran huruf hijaiyah, cara ini termasuk kurang disukai oleh para santri [5].

Pada penelitian implementasi augmented reality dengan metode marker based tracking pada media pembelajaran huruf hijaiyah yang diperuntukkan bagi 
anak-anak usia kelas satu sekolah dasar. Pada penelitian tersebut terdapat beberapa kekurangan yang harus diperhatikan yaitu penentuan indikator yang mempengaruhi keberhasilan aplikasi dalam memunculkan objek hijaiyah 3D [4].

Augmented reality berdasarkan metode pelacakan (tracking) terbagi menjadi dua, yaitu marker based tracking dan markerless. Kedua metode ini memiliki persamaan dalam hal memunculkan objek yaitu dipengaruhi oleh indikator jarak pendeteksian dan besarnya intensitas cahaya. Belum diketahui berapa jarak dan kondisi intensitas cahaya yang ideal bagi metode marker based tracking dan metode markerless dalam kaitan keberhasilan memunculkan objek virtual. Oleh karena itu, berdasarkan latar belakang tersebut, pada penelitian ini akan diimplementasikan metode marker based tracking dan metode markerless augmented reality pada pembelajaran huruf hijaiyah dan akan dilakukan analisis pada kedua metode tersebut terhadap pengaruh jarak pendeteksian dan intensitas cahaya dalam keberhasilan memunculkan objek virtual. Hasil yang diharapkan pada penelitian ini adalah diperolehnya jarak pendeteksian yang tepat dan kondisi intensitas cahaya yang ideal bagi kedua metode tersebut dalam memunculkan huruf hijaiyah $3 \mathrm{D}$.

\section{A. Huruf Hijaiyah}

Huruf-huruf yang dipergunakan dalam Al-Qur'an disebut 'huruf hijaiyah' yang berjumlah 29 huruf, yaitu [1].

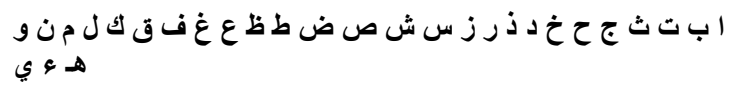

Pada penelitian ini, huruf hijaiyah tidak akan dimunculkan semuanya. Penelitian ini lebih difokuskan pada analisis dan pengujian dari metode marker tracking.

\section{B. Augmented Reality (AR)}

Augmented reality sebagai penggabungan benda benda nyata dan maya di lingkungan nyata, berjalan secara interaktif dalam waktu nyata, dan terdapat integrasi antar benda dalam tiga dimensi, yaitu benda maya yang terintegrasi dalam dunia nyata. Penggabungan benda nyata dan maya dimungkinkan dengan teknologi tampilan yang sesuai, interaktivitas dimungkinkan melalui perangkat-perangkat input tertentu, dan integrasi yang baik memerlukan penjejakan yang efektif [3].

\section{Metode Marker Tracking}

\section{Marker Based Tracking}

Marker based tracking adalah AR yang menggunakan marker atau penanda objek dua dimensi yang memiliki suatu pola yang akan dibaca komputer melalui media webcam atau kamera yang tersambung dengan komputer, biasanya merupakan ilustrasi hitam dan putih dengan batas hitam tebal dan latar belakang putih [6].

\section{Markerless}

Markerless merupakan sebuah metode pelacakan dimana dengan metode markerless pengguna tidak perlu lagi mencetak sebuah marker untuk menampilkan elemen-elemen digital. Dalam hal ini, marker yang dikenali berbentuk posisi perangkat, arah, maupun lokasi [6].

\section{Intensitas Cahaya Terhadap Warna Cahaya}

Intensitas cahaya adalah besaran pokok fisika untuk mengukur daya yang dipancarkan oleh suatu sumber cahaya pada arah tertentu persatuan sudut [2]. Dalam sebuah penelitian yang dilakukan oleh Yudiantika mengenai pengaruh karakteristik dan pencahayaan objek terhadap pelacakan tanpa penanda dalam ruang tertutup pada aplikasi mobile augmented reality, intensitas cahaya yang dihasilkan oleh beberapa warna lampu dengan daya yang sama besar ternyata menghasilkan intensitas cahaya yang berbeda. Semakin kecil nilai intensitas cahaya yang diterima luxmeter berarti cahaya yang dipancarkan oleh lampu semakin redup [7].

\section{METODOLOGI PENELITIAN}

Penelitian ini meneliti pemanfaatan metode marker based tracking dan metode markerless, kedua metode ini merupakan metode marker tracking pada sistem augmented reality. Penelitian ini akan mengambil fokus pada pengaruh intensitas cahaya dan jarak pendeteksian terhadap keberhasilan kedua metode tracking tersebut dalam memunculkan objek 3D.

Adapun rancangan sistem untuk metode marker based tracking dan metode markerless tersaji pada Gambar 1 dan 2,

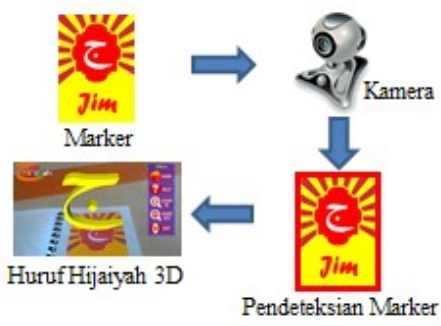

Gambar 1. Sistem Pada Metode Marker Based Tracking

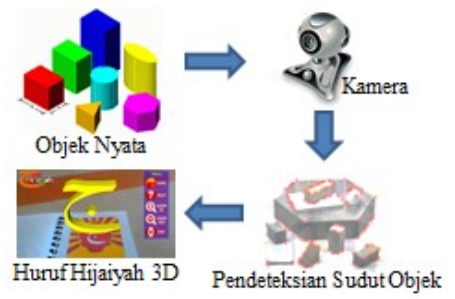

Gambar 2. Sistem Pada Metode Markerless 
Pengambilan data penelitian menggunakan metode percobaan uji aplikasi. Percobaan untuk memperoleh data primer berupa hasil pengujian berdasarkan parameter yang telah ditentukan yaitu intensitas cahaya dan jarak pendeteksian. Selain itu, dilakukan penelitian kepustakaan untuk memperoleh data sekunder yang mendukung penelitian ini seperti jurnal dan buku sebagai bahan rujukan.

\section{A. Teknik Pengujian}

Tahapan teknik pengujian secara lebih detail adalah sebagai berikut.

1. Menentukan kebutuhan pengujian.

2. Membangun aplikasi augmented reality dengan spesifikasi hardware ditentukan.

3. Instalasi aplikasi pada smartphone.

4. Pengujian dan pengambilan data percobaan dilakukan sesuai dengan indikator variabel yang ada yaitu intensitas cahaya dan jarak pendeteksian, dengan ketentuan, yaitu. a. Pengujian dilakukan dengan menggunakan marker huruf hijaiyah untuk metode marker based tracking.

b. Pengujian dilakukan dengan memanfaatkan berbagai benda dikehidupan sehari-hari untuk metode markerless.

c. Pengujian aplikasi akan dilakukan sebanyak 10x disetiap percobaan.

5. Analisis data hasil pengujian.

6. Merumuskan kesimpulan penelitian.

\section{B. Indikator Variabel}

Pada penelitian ini, pengujian aplikasi augmented reality akan dilakukan analisis terhadap pengaruh jarak pendeteksian marker serta pengaruh intensitas cahaya terhadap keberhasilan pendeteksian marker, namun dengan beberapa sub indikator yang berbeda. Adapun indikator variabel, sub indikator, dan skala pengukuran yang digunakan dapat dilihat pada Tabel 1.

Tabel 1. Indikator Variabel

\begin{tabular}{lll}
\hline Indikator Variabel & \multicolumn{1}{c}{ Sub Indikator Variabel } & Skala pengukuran \\
\hline & 1. Pendeteksian pada jarak $3 \mathrm{~cm}$ & \\
2. Pendeteksian pada jarak $5 \mathrm{~cm}$ & \\
3. Pendeteksian pada jarak $10 \mathrm{~cm}$ & \\
4. Pendeteksian pada jarak $20 \mathrm{~cm}$ & $\mathrm{~cm}$ \\
Jarak Pendeteksian & 5. Pendeteksian pada jarak $30 \mathrm{~cm}$ & \\
6. Pendeteksian pada jarak $40 \mathrm{~cm}$ & \\
7. Pendeteksian pada jarak $50 \mathrm{~cm}$ & \\
8. Pendeteksian pada jarak $80 \mathrm{~cm}$ & \\
9. Pendeteksian pada jarak $300 \mathrm{~cm}$ & \\
1. Sumber cahaya matahari & \\
2. Sumber cahaya berdasarkan & Intensitas \\
Intensitas cahaya & warna lampu \\
& - kuning, merah, hijau, biru, & \\
\hline
\end{tabular}

\section{HASIL PENELITIAN}

\section{A. Alat dan Bahan Pengujian}

Pengujian metode marker based tracking dan metode markerless menggunakan beberapa peralatan dengan spesifikasi tertentu. Adapun beberapa peralatan tersebut diantaranya.

\section{Smartphone}

$$
\begin{aligned}
& \text { - Processor : MediaTek 64-bit } 1.7 \mathrm{GHz} \\
& \text { True8Core }^{\mathrm{TM}} \\
& \text { - RAM : } 2.00 \mathrm{~GB} \\
& \text { - Memory : } 16 \text { GB ROM } \\
& \text { - VGA : } 5.0 \text { ” HD (1280 x 720) IPS } \\
& \text { - Kamera : } 13 \text { MP auto-focus }
\end{aligned}
$$

\section{Media Pengujian}

Sesuai dengan perencanaan sebelumnya, pengujian akan dilakukan dengan menggunakan dua indikator pengujian yaitu pengaruh jarak dan intensitas cahaya pada aplikasi augmented reality.
Berikut ini adalah persiapan sebelum melakukan pengujian yang tersaji pada Gambar 3 .
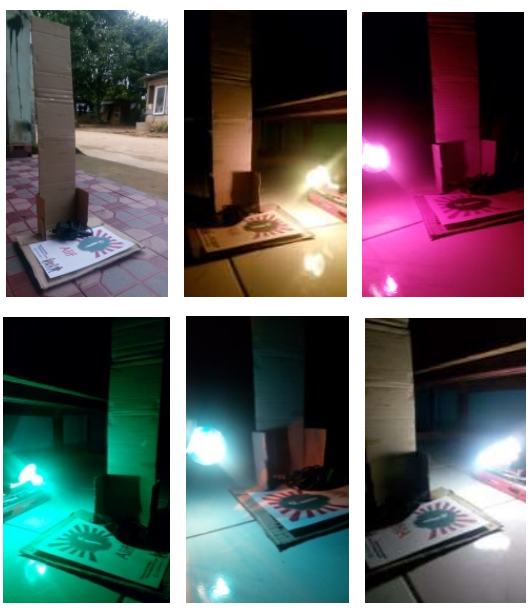

Gambar 3. Ilustrasi Pengujian 
Gambar 3 menunjukkan bahwa terdapat 6 macam pengujian yang dilakukan, yaitu menggunakan lampu berwarna kuning, merah, hijau, biru, terang, dan cahaya matahari.

Adapun spesifikasi dan ukuran yang menjadi marker (penanda) bagi kedua metode tracking dalam proses pengujian adalah sebagai berikut.

a. Metode marker based tracking

- Ukuran marker : A5 (14,8 cm x 21,0 cm)

- Jenis kertas : kertas cover (tebal)

b. Metode markerless

- Objek yang digunakan : charger handphone dan jam tangan.

- Ukuran diameter :

- Charger handphone: $\mathrm{p}=5.5 \mathrm{~cm} ; 1=$ $2.5 \mathrm{~cm} ; \mathrm{t}=7 \mathrm{~cm}$

- Jam tangan : diameter $=5 \mathrm{~cm}$

Dan adapun sumber yang digunakan sebagai indikator dalam menentukan intensitas cahaya adalah.

a. Sumber cahaya matahari

b. Lima jenis lampu dengan daya 15 watt yang memiliki variasi warna yaitu warna kuning, merah, hijau, biru, dan terang (putih).

Beberapa sumber diatas akan menghasilkan intensitas cahaya yang besarnya berbeda-beda sehingga akan didapatkan indikator intensitas cahaya yang mendukung dalam proses pengujian.

Kemudian dalam melakukan pengukuran intensitas cahaya pada sumber cahaya dan juga jarak pendeteksian digunakan alat sebagai berikut. a. Lux meter : alat ukur intensitas cahaya

b. Meteran : alat ukur jarak pendeteksian

Adapun lux meter dan juga meteran yang digunakan dalam proses pengujian tersaji pada Gambar 4.

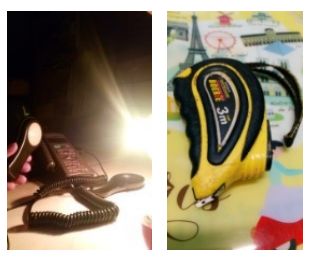

Gambar 4. Alat Pengukur Intensitas Cahaya dan Jarak

\section{B. Hasil Pengujian}

Hasil dari seluruh pengujian dibagi menjadi 6 (enam) bagian, yaitu.

1. Pengujian Jarak Terhadap Intensitas Sumber Cahaya Matahari

Pengujian ini dilakukan di teras rumah dengan kemiringan sudut $90^{\circ}$. Besarnya intensitas cahaya adalah 1605 lux. Hasil pengujian dapat dilihat pada Tabel 2.

Kesimpulan yang didapatkan pada Tabel 2 bahwa pada intensitas cahaya sebesar 1605 lux sistem berhasil melakukan pendeteksian objek 3D. Untuk metode marker based tracking memiliki jarak pendeteksian minimum $7 \mathrm{~cm}$ dan maksimum $88 \mathrm{~cm}$ serta metode markerless memiliki jarak pendeteksian minimum $3 \mathrm{~cm}$ dan maksimum 300 $\mathrm{cm}$.

Tabel 2. Hasil Pengujian Metode Tracking

\begin{tabular}{cccccccccccc}
\hline \multirow{2}{*}{ Metode Tracking } & \multicolumn{1}{c}{ Pengujian Jarak (cm) } & \multicolumn{1}{c}{ Ket. Jarak } \\
\cline { 2 - 12 } & $\mathbf{3}$ & $\mathbf{5}$ & $\mathbf{1 0}$ & $\mathbf{2 0}$ & $\mathbf{3 0}$ & $\mathbf{4 0}$ & $\mathbf{5 0}$ & $\mathbf{8 0}$ & $\mathbf{3 0 0}$ & J. Min & J. Max \\
\hline $\begin{array}{c}\text { Marker Based } \\
\text { Tracking }\end{array}$ & $\mathrm{T}$ & $\mathrm{T}$ & $\mathrm{Y}$ & $\mathrm{Y}$ & $\mathrm{Y}$ & $\mathrm{Y}$ & $\mathrm{Y}$ & $\mathrm{Y}$ & $\mathrm{T}$ & $7 \mathrm{~cm}$ & $88 \mathrm{~cm}$ \\
Markerless & $\mathrm{Y}$ & $\mathrm{Y}$ & $\mathrm{Y}$ & $\mathrm{Y}$ & $\mathrm{Y}$ & $\mathrm{Y}$ & $\mathrm{Y}$ & $\mathrm{Y}$ & $\mathrm{Y}$ & $3 \mathrm{~cm}$ & $300 \mathrm{~cm}$ \\
\hline
\end{tabular}

2. Pengujian Jarak Terhadap Intensitas Cahaya Lampu Kuning

Pengujian ini dilakukan di dalam kamar dengan sumber cahaya hanya lampu berwarna kuning dan kemiringan sudut $90^{\circ}$. Besarnya intensitas cahaya adalah 553 lux. Hasil pengujian dapat dilihat pada Tabel 3. Kesimpulan yang didapatkan pada Tabel 3 bahwa pada intensitas cahaya sebesar 553 lux. sistem berhasil melakukan pendeteksian objek. Untuk metode marker based tracking memiliki jarak pendeteksian minimum $7 \mathrm{~cm}$ dan maksimum 84 $\mathrm{cm}$ serta metode markerless memiliki jarak pendeteksian minimum $3 \mathrm{~cm}$ dan maksimum 300 $\mathrm{cm}$.

Tabel 3. Hasil Pengujian Metode Tracking

\begin{tabular}{cccccccccccc}
\hline & \multicolumn{1}{c}{ Pengujian Jarak (cm) } \\
\cline { 2 - 12 } Metode Tracking & $\mathbf{3}$ & $\mathbf{5}$ & $\mathbf{1 0}$ & $\mathbf{2 0}$ & $\mathbf{3 0}$ & $\mathbf{4 0}$ & $\mathbf{5 0}$ & $\mathbf{8 0}$ & $\mathbf{3 0 0}$ & J. Min & J. Max \\
\hline $\begin{array}{c}\text { Marker Based } \\
\text { Tracking }\end{array}$ & $\mathrm{T}$ & $\mathrm{T}$ & $\mathrm{Y}$ & $\mathrm{Y}$ & $\mathrm{Y}$ & $\mathrm{Y}$ & $\mathrm{Y}$ & $\mathrm{Y}$ & $\mathrm{T}$ & $7 \mathrm{~cm}$ & $84 \mathrm{~cm}$ \\
Markerless & $\mathrm{Y}$ & $\mathrm{Y}$ & $\mathrm{Y}$ & $\mathrm{Y}$ & $\mathrm{Y}$ & $\mathrm{Y}$ & $\mathrm{Y}$ & $\mathrm{Y}$ & $\mathrm{Y}$ & $3 \mathrm{~cm}$ & $300 \mathrm{~cm}$ \\
\hline
\end{tabular}


3. Pengujian Jarak Terhadap Intensitas Cahaya Lampu Merah

Pengujian ini dilakukan di dalam kamar dengan sumber cahaya hanya lampu berwarna merah dan kemiringan sudut $90^{\circ}$. Besarnya intensitas cahaya adalah 197 lux. Hasil pengujian dapat dilihat pada Tabel 4.
Kesimpulan yang didapatkan pada Tabel 4 bahwa pada intensitas cahaya sebesar 197 lux sistem berhasil melakukan pendeteksian objek. Untuk metode marker based tracking memiliki jarak pendeteksian minimum $10 \mathrm{~cm}$ dan maksimum $76 \mathrm{~cm}$ serta metode markerless memiliki jarak pendeteksian minimum $8 \mathrm{~cm}$ dan maksimum $300 \mathrm{~cm}$.

Tabel 4. Hasil Pengujian Metode Tracking

\begin{tabular}{|c|c|c|c|c|c|c|c|c|c|c|c|}
\hline \multirow{2}{*}{ Metode Tracking } & \multicolumn{9}{|c|}{ Pengujian Jarak (cm) } & \multicolumn{2}{|c|}{ Ket. Jarak } \\
\hline & 3 & 5 & 10 & 20 & 30 & 40 & 50 & 80 & 300 & J. Min & J. Max \\
\hline $\begin{array}{c}\text { Marker Based } \\
\text { Tracking }\end{array}$ & $\mathrm{T}$ & $\mathrm{T}$ & $\mathrm{Y}$ & $\mathrm{Y}$ & $\mathrm{Y}$ & $\mathrm{Y}$ & $\mathrm{Y}$ & $\mathrm{T}$ & $\mathrm{T}$ & $10 \mathrm{~cm}$ & $76 \mathrm{~cm}$ \\
\hline Markerless & $\mathrm{T}$ & $\mathrm{T}$ & $\mathrm{Y}$ & $\mathrm{Y}$ & $\mathrm{Y}$ & $\mathrm{Y}$ & $\mathrm{Y}$ & $\mathrm{Y}$ & $\mathrm{Y}$ & $8 \mathrm{~cm}$ & $300 \mathrm{~cm}$ \\
\hline
\end{tabular}

4. Pengujian Jarak Terhadap Intensitas Cahaya Lampu Hijau

Pengujian ini dilakukan di dalam kamar dengan sumber cahaya hanya lampu berwarna hijau dan kemiringan sudut $90^{\circ}$. Besarnya intensitas cahaya adalah 118 lux. Hasil pengujian dapat dilihat pada Tabel 5.
Kesimpulan pada Tabel 5 bahwa pada intensitas cahaya sebesar 118 lux sistem berhasil melakukan pendeteksian objek. Untuk metode marker based tracking memiliki jarak pendeteksian minimum $7 \mathrm{~cm}$ dan maksimum 75 $\mathrm{cm}$ serta metode markerless memiliki jarak pendeteksian minimum $3 \mathrm{~cm}$ dan maksimum $300 \mathrm{~cm}$.

Tabel 5. Hasil Pengujian Metode Tracking

\begin{tabular}{|c|c|c|c|c|c|c|c|c|c|c|c|}
\hline \multirow{2}{*}{ Metode Tracking } & \multicolumn{9}{|c|}{ Pengujian Jarak (cm) } & \multicolumn{2}{|c|}{ Ket. Jarak } \\
\hline & 3 & 5 & 10 & 20 & 30 & 40 & 50 & 80 & 300 & J. Min & J. Max \\
\hline $\begin{array}{c}\text { Marker Based } \\
\text { Tracking }\end{array}$ & $\mathrm{T}$ & $\mathrm{T}$ & $\mathrm{Y}$ & $\mathrm{Y}$ & $\mathrm{Y}$ & Y & $\mathrm{Y}$ & $\mathrm{T}$ & $\mathrm{T}$ & $7 \mathrm{~cm}$ & $75 \mathrm{~cm}$ \\
\hline Markerless & $\mathrm{Y}$ & Y & $\mathrm{Y}$ & $\mathrm{Y}$ & $\mathrm{Y}$ & $\mathrm{Y}$ & $\mathrm{Y}$ & $\mathrm{Y}$ & $\mathrm{Y}$ & $3 \mathrm{~cm}$ & $300 \mathrm{~cm}$ \\
\hline
\end{tabular}

5. Pengujian Jarak Terhadap Intensitas Cahaya Lampu Biru

Pengujian ini dilakukan di dalam kamar dengan sumber cahaya hanya lampu berwarna biru dan kemiringan sudut $90^{\circ}$. Besarnya intensitas cahaya adalah 97 lux. Hasil pengujian dapat dilihat pada Tabel 6 .
Kesimpulan yang didapatkan pada Tabel 6 bahwa pada intensitas cahaya sebesar 97 lux sistem berhasil melakukan pendeteksian objek dengan baik. Untuk metode marker based tracking memiliki jarak pendeteksian minimum $7 \mathrm{~cm}$ dan maksimum $75 \mathrm{~cm}$ serta metode markerless memiliki jarak pendeteksian minimum $3 \mathrm{~cm}$ dan maksimum $300 \mathrm{~cm}$.

Tabel 6. Hasil Pengujian Marker Based Tracking

\begin{tabular}{|c|c|c|c|c|c|c|c|c|c|c|c|}
\hline \multirow{2}{*}{ Metode Tracking } & \multicolumn{9}{|c|}{ Pengujian Jarak (cm) } & \multicolumn{2}{|c|}{ Ket. Jarak } \\
\hline & 3 & 5 & 10 & 20 & 30 & 40 & 50 & 80 & 300 & J. Min & J. Max \\
\hline $\begin{array}{l}\text { Marker Based } \\
\text { Tracking }\end{array}$ & $\mathrm{T}$ & $\mathrm{T}$ & $\mathrm{Y}$ & $\mathrm{Y}$ & $\mathrm{Y}$ & $\mathrm{Y}$ & $\mathrm{Y}$ & $\mathrm{T}$ & $\mathrm{T}$ & $7 \mathrm{~cm}$ & $75 \mathrm{~cm}$ \\
\hline Markerless & $\mathrm{Y}$ & Y & $\mathrm{Y}$ & $\mathrm{Y}$ & $\mathrm{Y}$ & $\mathrm{Y}$ & $\mathrm{Y}$ & $\mathrm{Y}$ & $\mathrm{Y}$ & $3 \mathrm{~cm}$ & $300 \mathrm{~cm}$ \\
\hline
\end{tabular}

6. Pengujian Jarak Terhadap Intensitas Cahaya Lampu Terang (Putih)

Pengujian ini dilakukan di dalam kamar dengan sumber cahaya hanya lampu berwarna terang (putih) dan kemiringan sudut $90^{\circ}$.
Besarnya intensitas cahaya adalah 435 lux. Hasil pengujian dapat dilihat pada Tabel 7.

Kesimpulan yang didapatkan pada Tabel 7 bahwa pada intensitas cahaya sebesar 435 lux sistem berhasil melakukan pendeteksian objek. Untuk metode marker based tracking memiliki 
jarak pendeteksian minimum $7 \mathrm{~cm}$ dan maksimum $85 \mathrm{~cm}$ serta metode markerless memiliki jarak pendeteksian minimum $3 \mathrm{~cm}$ dan maksimum $300 \mathrm{~cm}$.

Tabel 7. Hasil Pengujian Metode Tracking

\begin{tabular}{|c|c|c|c|c|c|c|c|c|c|c|c|}
\hline \multirow{2}{*}{ Metode Tracking } & \multicolumn{9}{|c|}{ Pengujian Jarak (cm) } & \multicolumn{2}{|c|}{ Ket. Jarak } \\
\hline & 3 & 5 & 10 & 20 & 30 & 40 & 50 & 80 & 300 & J. Min & J. Max \\
\hline $\begin{array}{c}\text { Marker Based } \\
\text { Tracking }\end{array}$ & $\mathrm{T}$ & $\mathrm{T}$ & $\mathrm{Y}$ & $\mathrm{Y}$ & $\mathrm{Y}$ & $\mathrm{Y}$ & $\mathrm{Y}$ & $\mathrm{Y}$ & $\mathrm{T}$ & $7 \mathrm{~cm}$ & $85 \mathrm{~cm}$ \\
\hline Markerless & $\mathrm{Y}$ & $\mathrm{Y}$ & $\mathrm{Y}$ & $\mathrm{Y}$ & $\mathrm{Y}$ & $\mathrm{Y}$ & $\mathrm{Y}$ & $\mathrm{Y}$ & $\mathrm{Y}$ & $3 \mathrm{~cm}$ & $300 \mathrm{~cm}$ \\
\hline
\end{tabular}

\section{Grafik Hasil Pengujian}

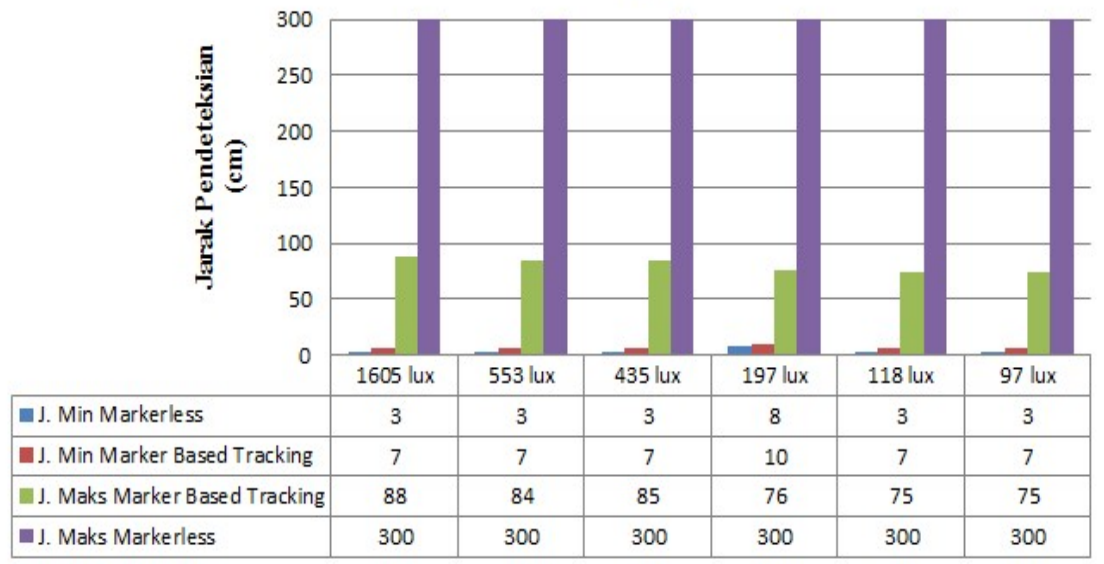

Gambar 5. Grafik Hasil Pengujian

\section{PEMBAHASAN}

\section{A. Analisis Hasil Pengujian}

Pengujian yang telah dilaksanakan untuk mengetahui pengaruh jarak pendeteksian dan intensitas cahaya terhadap keberhasilan metode marker based tracking dan metode markerless dalam memunculkan objek 3D. Untuk rangkuman hasil pengujian tersaji pada sebuah grafik yang ditunjukkan pada Gambar 5.

Sehingga dari grafik hasil pengujian pada Gambar 5 dapat diambil beberapa poin penting terkait hasil pengujian pengaruh jarak dan intensitas cahaya terhadap metode tracking pada sistem augmented reality adalah sebagai beikut.

1. Jarak memiliki pengaruh pada keberhasilan sistem dalam memunculkan objek. Terkait dalam keberhasilannya memunculkan objek, terdapat jarak ideal bagi kedua metode tersebut yang digolongkan pada jarak minimum dan jarak maksimum. Adapun hasil rata-rata jarak minimum maupun jarak maksimum dari kedua metode tracking dengan kondisi intensitas cahaya yang berbeda adalah untuk metode marker based tracking rata-rata jarak minimum yaitu pada jarak $7.5 \mathrm{~cm}$ dan rata-rata jarak maksimumnya yaitu pada jarak $80.5 \mathrm{~cm}$ Sedangkan pada metode markerless rata-rata jarak minimum yaitu pada jarak $3.8 \mathrm{~cm}$ dan untuk rata-rata jarak maksimumnya yaitu pada jarak $300 \mathrm{~cm}$.

2. Pada kondisi intensitas cahaya 97 lux hingga 1605 lux, metode marker based tracking maupun metode markerless dapat memunculkan objek 3D dengan baik.

3. Besarnya intensitas cahaya tidak berpengaruh pada penentuan jarak minimum maupun jarak maksimum pendeteksian marker.

\section{PENUTUP}

\section{A. Kesimpulan}

Kesimpulan yang dapat diambil dari hasil pengujian pada penelitian ini adalah sebagai berikut.

1. Jarak memiliki peranan penting pada keberhasilan augmented reality dalam memunculkan objek virtual 3D. Hal ini dapat dibuktikan pada hasil pengujian yang menunjukkan bahwa dalam memunculkan objek, untuk metode marker based tracking rata-rata jarak minimum pendeteksian berada pada jarak $7.5 \mathrm{~cm}$ dan jarak maksimumnya yaitu pada jarak $80.5 \mathrm{~cm}$. 
Sedangkan pada metode markerless, ratarata jarak minimum pendeteksian berada pada jarak $3.8 \mathrm{~cm}$ dan rata-rata jarak maksimumnya adalah $300 \mathrm{~cm}$.

2. Intensitas cahaya juga menjadi faktor keberhasilan bagi kedua metode tracking yaitu metode marker based tracking maupun markerless dalam memunculkan objek. Dari hasil pengujian didapatkan, pada kondisi intensitas cahaya yaitu 97 lux - 1605 lux sistem augmented reality dapat memunculkan objek virtual 3D dengan baik. Sehingga pada penerapannya, penelitian ini memberikan manfaat pada penentuan sumber cahaya sehingga didapatkan intensitas cahaya yang tepat bagi sistem dalam keberhasilannya memunculkan objek.

\section{B. Saran}

Saran untuk penelitian ini adalah:

1. Menambahkan indikator pengujian untuk aplikasi yaitu resolusi kamera, sudut kemiringan, waktu pendeteksian dan marker.

2. Menambahkan fitur aplikasi dengan penambahan animasi, face tracking, dan juga 3D recognition.

\section{DAFTAR PUSTAKA}

[1] Al-Buthoniyah, Ummu Abdillah, 2009, Belajar Menulis Huruf Hijaiyah, http://bam.raudhatulmuhibbin.org/2009/07/belajarmenulis-huruf-hijaiyah-1.html, 03 Juli 2009, di akses 22 Oktober 2015.

[2] Bala, Qhy, 2011, Intensitas Cahaya, http://www.scribd.com/doc/72993532/itensitascahaya\#scribd, diakses pada tanggal 19 Januari 2016 pukul 14.11 WIB.

[3] Edward, Jhon, 2014, Visualisasi Lingkungan Kampus Politeknik Negeri Batam Mengunakan Augmented reality, Skripsi, Prodi Multimedia dan Jaringan Jurusan Informatika Politeknik Negeri Batam, Batam.

[4] Huda, Miftakhul, 2015, Aplikasi Pembelajaran Huruf Hijaiyah Berbasis Augmented Reality,Proyek Akhir, Prodi Multimedia dan Jaringan Jurusan Informatika Politeknik Negeri Batam, Batam.

[5] Husaini, Fachri, 2013, Pembuatan Media Edukasi Ayo Bermain Huruf Hijaiyah Pada TPA AN-NUR Daleman, Proceeding Seminar Riset Unggulan Nasional Informatika dan Komputer FTI UNSA, Surakarta.

[6] Rahman, Abdur. dkk, 2014, Rancang Bangun Aplikasi Informasi Universitas Bengkulu Sebagai Panduan Pengenalan Kampus Menggunakan Metode Markerless Augmented Reality Berbasis Android, Jurnal Rekursif, 2, 2, 2303-0755.

[7] Yudiantika, Aditya Rizki, Selo, Sulistyo dan Bimo, Sunarfri, Hantono, 2014, Pengaruh Karakteristik dan Pencahayaan Objek terhadap Pelacakan Tanpa Penanda dalam Ruang Tertutup pada Aplikasi Mobile Augmented Reality, Proceeding CITEE, Yogyakarta, 7-8 Oktober 2014. 